ISSN 2409-2665

Journal of Logistics, Informatics and Service

Science Vol. 7 (2020) No. 1, pp. $42-57$

DOI: 10.33168/LISS.2020.0104

\title{
Identification of the Opportunities to Improve Customer's Experience in E-Commerce
}

\author{
Vida Davidavičienè ${ }^{1}$, Olena Markus ${ }^{2}$, Sigitas Davidavičius ${ }^{3}$ \\ ${ }^{1,2}$ Department of Business Technologies and Entrepreneurship, Faculty of Business \\ Management, Vilnius Gediminas Technical University, Sauletekio al. 11, LT-10223 \\ Vilnius, Lithuania \\ ${ }^{3}$ Department of Management, Faculty of Business Management, Vilnius Gediminas \\ Technical University, Sauletekio al. 11, LT-10223 Vilnius, Lithuania \\ ${ }^{1}$ vida.davidaviciene@vgtu.lt, ${ }^{3}$ sigitas.davidavicius@vgtu.lt
}

\begin{abstract}
Nowadays, the increased number of internet users forces a different kind of companies to expand their businesses and use the possibility to trade online. Nevertheless, going online requires a lot of effort from the company, including attention to details such as user experience and retention. Mainly, existing literature mostly describes the user as the most important factor for a business to gain higher profits in e-commerce sales. This research is aimed to evaluate the impact of defined criteria on a user's experience while making purchases on e-commerce websites. The paper observes and defines criteria that possibly could make an influence on customer's perception of e-commerce platforms. Defined criteria are examined by applying the AHP method in order to evaluate their importance according to the expert's opinion. To identify the impact of these criteria on the user's impression and to choose the best alternative was applied to another multi-criteria decision-making method - the TOPSIS. The main finding is that the nature of the user's experience does have an impact on how the consumer perceives the specific e-commerce platform. Although there were some limitations to evaluate the user's experience, they are owning to the fact that it needed to assess and proceed with more data that includes other influencing factors. The results of this research can be used in e-commerce, trading, and service companies as a tool to appraise to choose the way of developing websites for trading.
\end{abstract}

Keywords: E-commerce, e. consumer, e. consumer behavior, usability. 


\section{Introduction}

Nowadays, the information is a crucial driver factor of business and economy in general. It is hard to separate mostly any business activity from analyzing customer behavior or other information that could have an influence on the result. Moreover, nowadays, businesses can use all the advantages that are brought to everyday life on the Internet. Therefore, the Internet is the technology which changed the daily life and businesses over the globe. The rising efficiency of e-commerce for business is doubtful, but this has caused the necessity to search for alternative solutions and innovative way for selling more goods and services using online platforms. The distributors are employing the e-commerce to find new suppliers and reduce product prices. The vendors are using online platforms to extend the circle of customers, to propose new services, and improve performance efficiency maintaining the same level of product and service quality but at becoming able to reduce the price.

Undoubtedly, the essential benefits of e-commerce business are defined by its ability to meet the needs of companies and consumers to optimize the trading process. For instance, there are possibilities to lower the costs while enhancing the quality of products and services and developing a faster delivery system. The main advantage of e-commerce is to make goods easier to explore and buy through online retailers and marketplaces. Various businesses receive benefits from online trading that allows them to sell their products and services with the scope that was unavailable while only offline possibilities were used.

Offline shopping usually is accompanied by spending priceless time to search for goods in different shops or wandering between commodity shelves. In comparison, e-commerce proposes the opportunity to save time and approach all the customers need during an online session. Websites can leverage and exploit user's browse and purchase history in order to personalize product recommendations. The website visitors are the main component for a business to achieve more benefits, including higher profit in e-commerce.

The topicality of the work lies in the field of the problem that e-commerce websites have to be made in the most efficient and ergonomic way in order to attract more customers and retain existing ones. Consequently, understanding customer insights will allow businesses to be able to deliver what the customers want to achieve; therefore, this is the crucial step in raising a company's efficiency. The research object of the study is the customer's experience of using services while buying goods online.

The purpose of the study is to evaluate the impact of usability of e-commerce websites on customer's experience. In order to achieve the goal of the study, further tasks have to be accomplished: to review the literature to identify the key factors of success in e-commerce; to inspect the most applicable methods of measurement of key factors that could make an impact on customer's experience; using these 
methods to investigate most significant factors that have an impact on user's experience in Lithuania's e-commerce websites.

In this study, such methods of research are applied: analysis of literature and multi-criteria decision analysis. The results of this research could be implemented in the e-commerce, trading and service companies as a tool to choose the most appropriate way of using collected data and customer's data analytic for enhancing the efficiency of business processes. However, there are some barriers and challenges while running this study. Because it needed to assess and proceed with more data that includes other influencing factors, this study could be extended and a web-based survey processed in the future involving representative sample fusers.

\section{Literature Review}

Mainly, in offline shopping, the effect that the retailer does on the customer depends on the success of the live interaction. Contradictory, in the e-commerce business, the impression of the retailer stands on the design and usability of the website. Ecommerce has influenced retail sector and began era of dramatical changes based on increased data usage and analysis in the processes.

Table 1: Comparison of definitions of the term "E-commerce"

\begin{tabular}{|c|c|}
\hline Source & Definition \\
\hline Coppel, 2000 & $\begin{array}{l}\text { E-commerce is doing business in the Internet, selling goods and services } \\
\text { which are delivered offline as well as products which can be "digitized" } \\
\text { and delivered online, for example software. Activity can be business to } \\
\text { businesses or businesses to consumer. }\end{array}$ \\
\hline Ngai and Wat, 2002 & $\begin{array}{c}\text { E-commerce can be analyzed from a business process perspective, than it } \\
\text { can be characterized as is the application of technology toward the } \\
\text { automation of business transactions and workflow. }\end{array}$ \\
\hline Travis, 2002 & $\begin{array}{l}\text { E-commerce is the latest development that attempts to persuade } \\
\text { customers that technology will make their lives easier. }\end{array}$ \\
\hline $\begin{array}{c}\text { DeLone and } \\
\text { McLean, } 2004\end{array}$ & $\begin{array}{l}\text { E-commerce is defined as the use of the Internet to facilitate, execute, } \\
\text { and process business transactions, which involve a buyer and seller and } \\
\text { the exchange of goods or services for money }\end{array}$ \\
\hline $\begin{array}{l}\text { Karavdic and } \\
\text { Gregory, } 2005\end{array}$ & $\begin{array}{l}\text { E-commerce can be defined as an environment for pre-sending, trading, } \\
\text { distributing, servicing customers, collaborating with business partners, } \\
\text { and conducting transactions using electronic technologies }\end{array}$ \\
\hline $\begin{array}{l}\text { Huang, Dai, and } \\
\text { Liang, } 2014\end{array}$ & $\begin{array}{l}\text { E-commerce allows electronic payments and transactional information to } \\
\text { be transferred via the Internet. }\end{array}$ \\
\hline $\begin{array}{l}\text { Kannaiah, Desti, } \\
2015\end{array}$ & $\begin{array}{l}\text { E-commerce offers a level playing field and consumers face the efforts of } \\
\text { the e-tailers to present products/services. }\end{array}$ \\
\hline Damak, 2018 & $\begin{array}{l}\text { E-commerce is revolutionizing supply chain management and has } \\
\text { enormous potential for manufacturing, retail and service operations. }\end{array}$ \\
\hline
\end{tabular}


Irreversible changes are made by e-commerce for retail, services, and international business strategies. There are no doubts e-commerce will impact the processes of selling and marketing as well as purchase models of costumers. (Awiagah, Kang, and Lim, 2016). To understand the concept of e-commerce is important for achieving the aim of this study. Observation of scientific literature, represented in Table 1, has brought a vast of meanings that is included in the term "E-commerce".

Comparing different understandings and e-commerce definitions can be stated that e-commerce deals with the information exchange, transaction of goods and services, and includes payments. Cox and Dale (2001) mentioned that the main distinction between the physical service environment and the website interface is the ability of customization of the services to needs of individuals that companies have. Range of researchers focuses on the evaluation of the quality of website (Davidavičienè, Sabaitytè, and Davidavičius, 2017; Kirk and Abrahams, 2017; Knezevic, Davidaviciene, and Skrobot, 2017; Moreno et al., 2016), and the customer behavior (Claudy, Garcia, and O'Driscoll, 2015; Laudon and Traver, 2016; Saridakis et al., 2015). The peculiarities of navigation and perception of the quality of e-commerce in Lithuania were analyzed by Davidaviciene, Pabedinskaite, and Davidavicius (2017), Davidavičienè, Sabaityte, and Davidavičius (2017). According to DeLone and McLean (2004), companies that deal with e-commerce are forced to examine the performance of their business. Efficient e-commerce is considered to be one of the main components that can lead a company to successful activities. This information plays a vital role in e-commerce businesses, which can better serve the customer. There are split up of particular analytics tools for separate data and information following different approaches that are presented by scientists (Singh, Pandita, Kalyanaraman, and Chhabra, 2018).

Furthermore, usability of e-commerce is a complex problem involving humancomputer interaction, software engineering, and cognitive psychology (Tucker, 2008). Moreover, Zhang et al. (2011) states that online buying cosidered to be two stage process: the first stage is focused on encouraging customers to make a purchase online, and next to repurchase, which is strongly important for success of e-commerce vendor.

Travis (2002) says that a range of factors such as: slow response, unhelpful graphics, hidden functionality, and unreliable links can affect customer's patience and push it to the limit even before the purchase. The feedback which is often incomplete or is not present at all is also of high importance. Providing example of a real store author emphasizes that it is extremely easy to walk away from ecommerce website - it's the matter of few clicks. Therefore, according to previous research, proper usability testing is often omitted in e-commerce due to high cost and time consumption (Bias and Mayhew, 2005). Ranganathan and Ganapathy (2002) discovered that costumer's perception of the trustworthiness and abilities of 
e-commerce depends on quality of website, also quality of a website does impact on the willingness of users to transact with the business. Moreover, as Hasan et al. (2009) mentioned, that success of an e-commerce site is partly dependent on the ease of use. Therefore, it is vital to employ solutions like web analytics to measure and improve the usability of the websites.

Scholars are presenting consumer needs as a desire related to a value that can be identified as typical for product or service category in functional and emotional level in a exact situation when a product or service should maximize personal consumer's benefits (Davidavičienè et al., 2019). Key components that influence the way users perceive experience from interactions with websites are presented in Figure 1.

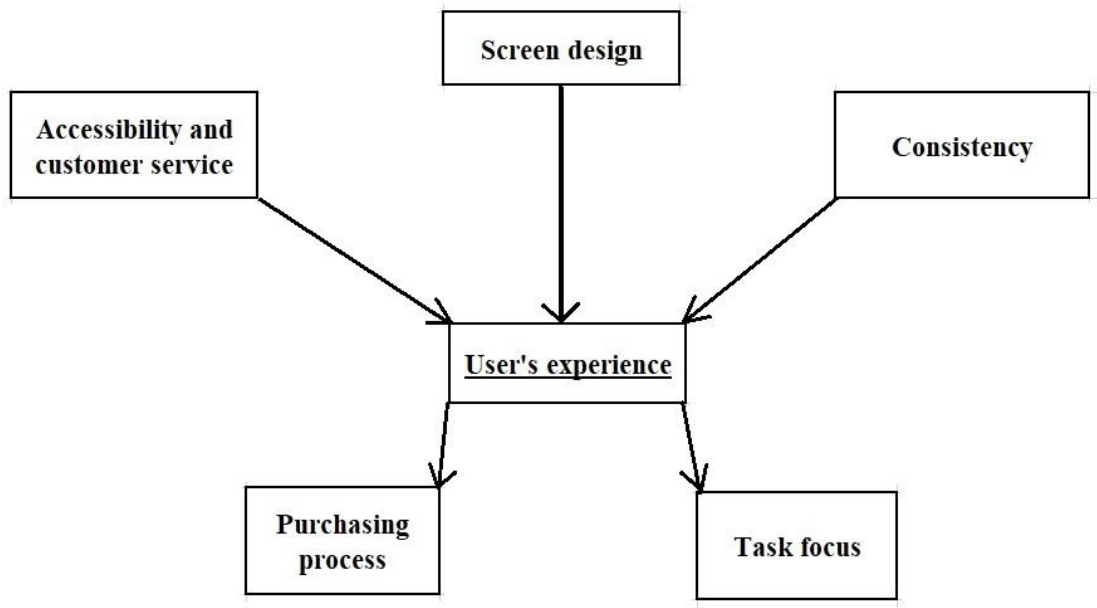

Fig. 1: Components that make an impact on a user's experience in E-commerce (Hasan et al., 2012; Travis, 2002)

These components reflect the major factors that could appear in various interpretations according to the user's impression while visiting websites. In this research, these indicators were pictured more precisely according to the way users describe their routine interactions. The identification of the factors influencing the performance of the website is necessary for proper website development, to ensure presence of specific design parameters and suitable performance-influencing features within the website (Tarafdar and Zhang, 2007). Although, there is a plethora of components that hypothetically can make an influence on the user's feelings during the interaction with the website. In general, usability is important for any kind of software which enables interaction with end user, such as: a website, a mobile commerce application, a software program, and a user-used-device based on a user's experience (Panda et al., 2015). Tullis, T. and Albert, W. (2008) 
emphasized the difference of usability and user experience. Usability is considered as the ability of the person to carry out a task successfully, and user experience requires a broader perception and is related to personal characteristic such as interaction, communication, openness, thoughts, feelings, and understanding of perceived data.

Understanding the features that can negatively influence on user's experience could have a positive effect on a whole business process. As Pappas et al. (2017) underlined that information processing theory emphasize the important aspect of perceiving and understanding the information, and according this theory each person (user) may tret the same information differently because of their own expertise. That's a reason of different reactions, attitude and behavior. In this study, we have inspected the study of two criteria of successful user experience by different authors (Table 2).

Table 2: Observation of user's experience factors of influence

\begin{tabular}{|c|c|c|}
\hline Criteria & Author & Definition \\
\hline \multirow{4}{*}{ 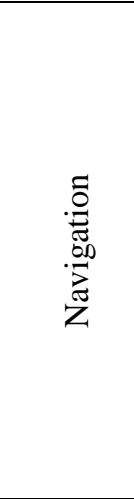 } & Preece, 2001 & $\begin{array}{l}\text { The simplicity with which the user can move around and find } \\
\text { what they looking for in the website is an important determinant } \\
\text { of success. }\end{array}$ \\
\hline & $\begin{array}{l}\text { Ranganathan and } \\
\text { Ganapathy, } 2002\end{array}$ & $\begin{array}{l}\text { Delays in searching or in loading a web page might cause the } \\
\text { consumers loss, when they give preference to other - faster } \\
\text { websites. }\end{array}$ \\
\hline & $\begin{array}{c}\text { Kuan, Bock, and } \\
\text { Vathanophas, } 2005\end{array}$ & $\begin{array}{l}\text { System quality can include the characteristics of an e-commerce } \\
\text { system, such as ease of navigation and download delay. }\end{array}$ \\
\hline & $\begin{array}{l}\text { Green and Pearson, } \\
2011\end{array}$ & $\begin{array}{l}\text { Highly navigable interfaces, decrease error rates and learning } \\
\text { time and increase performance and user satisfaction. }\end{array}$ \\
\hline \multirow{4}{*}{ 己ृ } & $\begin{array}{l}\text { Ranganathan and } \\
\text { Ganapathy, } 2002\end{array}$ & $\begin{array}{l}\text { Content refers to the information, features, or services offered in } \\
\text { the website, while the design is the way by which the contents } \\
\text { is presented to consumers. }\end{array}$ \\
\hline & $\begin{array}{l}\text { Tarafdar and } \\
\text { Zhang, } 2007\end{array}$ & $\begin{array}{l}\text { The most important characteristic for website design as far as } \\
\text { Website Reach is concerned is related to the content of the } \\
\text { information and the manner in which it is arranged. }\end{array}$ \\
\hline & $\begin{array}{l}\text { Ahn, Ryu, and } \\
\text { Han, } 2007\end{array}$ & $\begin{array}{l}\text { Information quality has a positive impact on perceived ease of } \\
\text { use and usefulness so user-customization and interactive media } \\
\text { contents should be provided for better results. }\end{array}$ \\
\hline & $\begin{array}{l}\text { Hernández, } \\
\text { Jiménez, and } \\
\text { Martín, } 2009\end{array}$ & $\begin{array}{l}\text { Website content is a factor that influences user's satisfaction } \\
\text { since the information provided on the website must be accurate, } \\
\text { informative, up to date, and relevant to customers' requirements. }\end{array}$ \\
\hline
\end{tabular}

Website usability and consumer experience online are closely connected. The usability of user interfaces (UI) of e-commerce websites is vital for the success 
operating online. The attracting attention of customers to e-commerce website, then providing interesting and relevant content, ease of use and quick reaction. However, studies show that almost all of the UI of e-commerce websites facing challenges with assuring usability (Zhao et al., 2007; Davidavičienè et al., 2019). These aspects will be analyzed further in empirical investigation.

\section{Methodology}

A lot of usability evaluation methods (UEMs) for software can be detected, because these methods became a part of the layout and improvement cycle that cannot be excluded in Web design. The methods can be classified to two types: user-targeted and expert-targeted. User-centered methods incorporate the methods that include interview, questionnaire, usability testing, focus groups, observations, eye-tracking or experiment to study customers' attitudes concerning interface design to discover issues regarding usability (Hui-Jiun, Jen and Shing-Sheng, 2008). Expert-targeted methods consist of the heuristic evaluation completed through one or several usability experts on a interface to perceive probable troubles and propose suggestions regarding the layout.

Cognitive walkthroughs $(\mathrm{CW})$ and heuristic evaluation $(\mathrm{HE})$ could be presented as expert-focused methods. First method, CW, evaluates the degree of difficulty to perform tasks while using the system to identify the moves and aims needed to finish every task (Khajouei et al., 2017). CW is a task-oriented and structured method that concentrates on the easiness of a system for brand new users. In this approach, experts via an interface step by step are completing the tasks. Meanwhile, they look at how easy it is for new users to accomplish an assignment with the system. CW could be applied to study complicated user interactions and goals (Polson et al., 1992; Wharton et al., 1994). The second method, HE, according to Brejcha (2015), is made by observing an interface and seeking to provide an opinion about what is good and bad about the interface. Ideally, users would conduct such opinions in accordance to certain rules, such as those indexed in typical guidelines documents. Although, most people probably carry out a heuristic evaluation on the premise of their personal instinct and commonplace feel instead. Delice and Gungor (2009) outline HE as a process wherein a small set of evaluators judge whether each assignment detail in a gadget conforms to established usability principles. HE's are commonly performed independently with the aid of the experts; every evaluator make an examine the interface and interaction on their own inorder to identify usability gaps. After the assessment, for each expert the severity score questionnaire were provided, where experts make notes on on usability issues that had been noticed. All assessors can then determine the solution to each problem.

Several usability issues were described by Nielsen (1994) as a mixture of 3 factors: frequency, effect and persistence. The severity ranking is not always performed in $\mathrm{HE}$ but is acquired from all of the experts. It would increase the 
reliability of the results, although it is not conducted in every HE. The 0-4 score scale proposed for evaluate the severity of usability problems by Nielsen (1994b). 0 displays the absence in this scale of the problem with the interface, on the contrary, 4 points show that there may be a big problem, and it's far vital to be fixed.

Comparison of these two methods by Khajouei et al., 2017 showed that CW is more efficient while evaluating and identifying the usability issues that are linked to the easiness of learnability for the new users. Although, HE method is more suitable in order to find usability issues that can influence user's satisfaction.

For this research, it was proposed in some way to combine these evaluation methods, but building different approach while measuring user's experience. Also, it would be useful to define a direct description of the user's negative experience and to make it easier for perception. The set of criteria was proposed for that purpose. These criteria let evaluate consumer's experience while using an e-commerce website. Although, all of them can be attributed to the concept - navigation and content. Criteria of negative user's experience are: (1) complicated website navigation; (2) having to fill out the same information twice; (3) unable to changelmodify the order; (4) unable to find relevant filters; (5) too many form fields to fill in; (6) unable to log-in via social network.

Thus, user experience is important as it helps to retain consumers if the experience is positive. Moreover, a meaningful user experience allows the owner of a business to identify and evaluate customer journeys in website that are most contributive to the company's prosperity. Having in mind the fact that for any ecommerce site, the audience is the main factor of its success, it is necessary to conduct interviews of existing and potential users to understand what is the most efficient design. Because the user experience is subjective, the best way is direct access to information through learning and interaction with the user.

The goal of this research, firstly, was to identify the key criteria that have an impact on the user's experience while making purchases. Secondly, it was necessary to evaluate how these criteria influence the impression of using four Lithuanian online marketplaces, namely: senukai.lt; skelbiu.lt; topocentras.lt; skytech.lt. For the research, it has been conducted an expert survey ( 5 experts were involved). Experts prioritized the importance of presented criteria and to assessed chosen marketplaces according to previously supplied criteria.

In order to define which criterion is more important than others, there was used the Analytic Hierarchy Process (AHP). AHP is a multi-criteria decision making (MCDM) method helping decision-makers in complex phenomenon with multiple conflicting and subjective criteria (e.g. location or investment selection, projects ranking, etc.) (Ishizaka and Labib, 2011). What is more, the view of experts has to be checked, whether it is consistent or not. When lot of pairwise comparisons are evaluated, the inconsistencies can appear. In order to discover the best alternative among the observed websites, it was chosen to apply another multi-criteria decision 
making (MCDM) method - the TOPSIS (Technique for Order Preference by Similarity to the Ideal Solution). The TOPSIS selects the alternative closest to the ideal solution and farthest from the negative ideal alternative. This method is based on information on an attribute from decision-maker, numerical data; the solution is aimed at evaluating, prioritizing and selecting and the only subjective inputs are weights (Ishizaka and Labib, 2011). The steps in calculating the TOPSIS method (Opricovic and Tzeng, 2004): Calculate the normalized decision matrix, then the weighted normalized decision matrix. To determine the ideal and negative-ideal solution. Calculate the separation measures, using the n-dimensional Euclidean distance. Calculate the relative closeness to the ideal solution. And finally, to rank the preference order. To sum up, after generating and evaluating the alternatives, such an MCDM method as TOPSIS was applied to rank alternatives and to propose a solution to the decision-maker.

\section{Results}

In order to test the significance of criteria that have been identified and presented in Part 1, five experts were asked to give their evaluation of the criteria's pairwise comparison. Every expert has made 15 decisions according to the number of pairs. Further calculation of five assessments, using the AHP method had shown results presented in Table 3. The final result of evaluation among all experts was calculated as the arithmetic average. The calculations discovered that the largest weight is obtained by the criterion "Unable to find relevant filters" $-45 \%$ and by the criterion "Complicated website navigation" - $22 \%$, the smallest weight reaches by criterion "Having to fill out the same information twice" - 5\%. Therefore, customers are more interested in having the ability to easily navigate through the website in order to receive the needed result. Although, the possible requirement to reenter the same information, to make an order again due to unavailability to change it, or the need to fill in much information can distract users and bring undesirable experience. Moreover, there was investigated the consistency of expert assessment (Table 4). All ratio values are lower than $10 \%$. It indicates that we could rely on the expert's opinions.

Determination of best alternative from supplied e-commerce websites by TOPSIS method. In this part of research, 5 experts were asked to evaluate websites mentioned in paragraph 2 using scores from 1 to 6 , that reflect further characteristics: 1 - Perfect, 2 - Very Good, 3 - Good, 4 - Average, 5 - Bad, 6 Very Bad. The results of 5 assessments were processed in order to find the arithmetic average from the sum of all expert's answers (Table 5). As it can be seen from the table the worst value $-5,8$ points received website www.skelbiu.lt over the criterion "Having to fill out the same information twice" Additionally, this website has got 5, 0 points in assessment over criteria "Unable to find relevant filters" and "To many form fields to fill in to fill in". Although, at the same time 
www.skelbiu.lt have received the best score 1,8 points over criterion "Unable to log-in via social network". Thus, www.senukai.lt have obtained the same score in "Having to fill out the same information twice" and "Unable to log-in via social network".

Table 3: Summary of calculation applying the AHP method

\begin{tabular}{|c|c|c|c|c|c|c|c|}
\hline Criteria & Value & Expert 1 & Expert 2 & Expert 3 & Expert 4 & Expert 5 & $\begin{array}{c}\text { The average } \\
\text { weight of } \\
\text { criteria }\end{array}$ \\
\hline $\begin{array}{c}\text { Complicated } \\
\text { website } \\
\text { navigation }\end{array}$ & $\begin{array}{c}\text { Eigen } \\
\text { vector }\end{array}$ & 0,24 & 0,30 & 0,22 & 0,19 & 0,15 & 0,22 \\
\hline $\begin{array}{c}\text { Having to fill } \\
\text { out the same } \\
\text { information } \\
\text { twice }\end{array}$ & $\begin{array}{c}\text { Eigen } \\
\text { vector }\end{array}$ & 0,05 & 0,03 & 0,05 & 0,07 & 0,07 & 0,05 \\
\hline $\begin{array}{c}\text { Unable to } \\
\text { changelmodify } \\
\text { the order }\end{array}$ & $\begin{array}{c}\text { Eigen } \\
\text { vector }\end{array}$ & 0,07 & 0,06 & 0,07 & 0,08 & 0,08 & 0,07 \\
\hline $\begin{array}{c}\text { Unable to find } \\
\text { relevant filters }\end{array}$ & $\begin{array}{c}\text { Eigen } \\
\text { vector }\end{array}$ & 0,46 & 0,41 & 0,49 & 0,46 & 0,43 & 0,45 \\
\hline $\begin{array}{c}\text { Too many form } \\
\text { fields to fill in }\end{array}$ & $\begin{array}{c}\text { Eigen } \\
\text { vector }\end{array}$ & 0,06 & 0,09 & 0,05 & 0,05 & 0,08 & 0,07 \\
\hline $\begin{array}{c}\text { Unable to log-in } \\
\text { via social } \\
\text { network }\end{array}$ & $\begin{array}{c}\text { Eigen } \\
\text { vector }\end{array}$ & 0,12 & 0,10 & 0,12 & 0,15 & 0,19 & 0,14 \\
\hline SUM & 1,00 & 1,00 & 1,00 & 1,00 & 1,00 & 1,00 \\
\hline
\end{tabular}

The next step was to apply the TOPSIS method to investigate the ideal solution. It should be mentioned that calculations take into account that all values of criteria have to be minimized. Computing data by the TOPSIS method showed (Table 6) that, according to this research, the preferable marketplace for online shopping is www.senukai.lt, due to the fact that it has gained the biggest score $(0,87)$. This website, according to experts' evaluation, has the best navigation and friendly to customers interface while making orders. Furthermore, the second participant received 0, 67 points, which is $23 \%$ smaller than the leading position.

According to the expert's evaluation, this website brings to users some inconvenience with registration and complexity with fulfilling the forms. In comparison, the last place was taken by www.skelbiu.lt by 0,32 points, which is $63 \%$ smaller than the first position. This website in accordance with expert evaluation faces the issues with the complicated navigation and with the need to 
write too much information. These results practically showed us that user's experience in one or another way could make an impact on how consumers perceive the website in general.

Table 4: Examination of the consistency of the expert's rating

\begin{tabular}{|c|c|c|c|c|c|}
\hline Expert No & Expert 1 & Expert 2 & Expert 3 & Expert 4 & Expert 5 \\
\hline Consistence ratio & 0,059 & 0,030 & 0,086 & 0,099 & 0,096 \\
\hline
\end{tabular}

Table 5: Summary of expert's evaluation of websites according to criteria

\begin{tabular}{|c|c|c|c|c|c|c|}
\hline Websites/Criteria & $\begin{array}{c}\text { Complicated } \\
\text { website } \\
\text { navigation }\end{array}$ & $\begin{array}{c}\text { Having to } \\
\text { fill out the } \\
\text { same } \\
\text { information } \\
\text { twice }\end{array}$ & $\begin{array}{c}\text { Unable to } \\
\text { changelmodify } \\
\text { the order }\end{array}$ & $\begin{array}{c}\text { Unable } \\
\text { to find } \\
\text { relevant } \\
\text { filters }\end{array}$ & $\begin{array}{c}\text { Too } \\
\text { many } \\
\text { form } \\
\text { fields } \\
\text { to fill in } \\
\text { to fill in }\end{array}$ & $\begin{array}{c}\text { Unable to } \\
\text { log-in via } \\
\text { social } \\
\text { network }\end{array}$ \\
\hline Weights of criteria & 0,22 & 0,05 & 0,07 & 0,45 & 0,07 & 0,14 \\
\hline www.senukai.lt & 2,4 & 1,8 & 2,2 & 3,0 & 3,6 & 1,8 \\
\hline www.skelbiu.lt & 4,6 & 5,8 & 3,8 & 5,0 & 5,0 & 1,8 \\
\hline www.topocentras.lt & 3,0 & 2,6 & 2,6 & 2,6 & 4,4 & 5,2 \\
\hline www.skytech.lt & 5,0 & 2,4 & 2,6 & 4,0 & 4,0 & 2,0 \\
\hline
\end{tabular}

Table 6: The result of calculations of the best alternative among supplied websites

\begin{tabular}{|c|c|c|}
\hline Website & Score & Rank \\
\hline www.senukai.lt & 0,87 & 1 \\
\hline www.topocentras.lt & 0,67 & 2 \\
\hline www.skytech.lt & 0,47 & 3 \\
\hline www.skelbiu.lt & 0,32 & 4 \\
\hline
\end{tabular}

\section{Conclusion}

In the modern world, it is almost impossible to ignore the fact that those who control and analyze information in the right way will always be able to stay at the forefront of developing efficient products and services. Furthermore, for businesses that want to expand their activity to the online market, it is crucial to develop an effective website that could attract and retain consumers. The success of one or another E-commerce website in the nearest future will depend on how good it was made, firstly, to make customers want to stay on the page and, what is more, to 
make an order. Secondly, it will depend on its ability to make users come back to the website one more time. In order words, a successful e-commerce website is the one that retains customers. Therefore, if the user cannot try and touch products the way it is possible during the usual shopping, the primary approach to get the customers' attention is to develop the interface that will attract users and will bring the best experience in comparison with competitors. So, before launching the ecommerce website, it is better to evaluate how user's precept it. For this reason, there could be used user- and expert centered evaluation techniques.

Such methods, at a different cost, will build a basic understanding of the customer's impression while experiencing various tasks and issues. Mainly, this research identified five criteria of user experience that could make a positive or negative impact on the user's experience. These criteria were evaluated by experts and, using the AHP method. It was defined which one criterion is more important than others. According to calculations of expert's opinions, the most detrimental factors that can spoil the positive experience are "Impossibility to log-in via social network" and "Impossibility to log-in via social network". Those factors had the largest effect on the user's perception and potentially on the desire to buy something. Furthermore, in this research, evaluated criteria were applied to determine the best website among some alternatives. The application of another multi-criteria decisionmaking method - TOPSIS, had helped to establish that in this particular research, users have received the best experience while visiting the website www.senukai. lt, and the worst experience was observed while visiting www.skelbiu.lt. Therefore, it is crucial for the developers and owners of e-commerce sites to give attention to research on improving the website environment in order to make the user's experience more exceptional. Further research could be aimed to investigate how the user's experience is altering according to the measures of improvement that were taken by owners of websites.

\section{References}

Ahn, T., Ryu, S., and Han, I. (2007). The impact of Web quality and playfulness on user acceptance of online retailing. Information and Management, 44(3), 263-275. https://doi.org/10.1016/j.im.2006.12.008

Awiagah, R., Kang, J., and Lim, J. I. (2016). Factors affecting e-commerce adoption among SMEs in Ghana. Information Development, 32(4), 815-836. https://doi.org/10.1177\%2F0266666915571427

Bias, R. G., and Mayhew, D. J. (2005). Cost-justifying usability: An update for the Internet age. San Francisco: Morgan Kaufmann. 
Brejcha, J. (2015). Heuristic Evaluation. Cross-Cultural Human-Computer Interaction and User Experience Design, (April), 163-166. https://doi.org/10.1201/b18059-15

Claudy, M. C., Garcia, R. O'Driscoll, A. (2015). Consumer Resistance to Innovation-a Behavioral Reasoning Perspective. Journal of the Academy of Marketing Science, 43 (4), 528-44. http://link.springer.com/10.1007/s11747-0140399-0 (March 23, 2017).

Coppel, J. (2000). E-Commerce: Impacts and Policy Challenges. OECD Economics Department Working Papers, (252), 1-26. https://doi.org/10.1787/801315684632

Cox, J., and Dale, B. G. (2001). Service quality and e-commerce: An exploratory analysis. Managing Service Quality: An International Journal, 11(2), 121-131. https://doi.org/10.1108/09604520110387257

Damak, D. (2018). A Revolutionizing Supply-Chain Management. International Business Research, 11(4), 84. https://doi.org/10.5539/ibr.v11n4p84

Davidavičienė V., Davidavičius S., and Kaušinis J. (2019). Consumer dissatisfaction structure - e-logistic perspective: Lithuania case. International journal of learning and change, 11(3), 237-251.

Davidaviciene, V., Pabedinskaite, A., Davidavicius, S. (2017). Social Networks in B2B and B2c Communication. Transformations in Business and Economics, 16(1): 69-84.

Davidavičienè, V., Sabaityte, J., and Davidavičius, S. (2017). Features of Food Industry on the Internet: A Case of Lithuania. In Challenges for International Business in Central and Eastern Europe, ed. N Wach, K., Knežević, B., and Šimurina. Kraków: Cracow University of Economics, 197-209. file:///C:/Users/1939/Downloads/1243-2970-1-PB.pdf (December 1, 2017

DeLone, W. H., and McLean, E. R. (2004). Measuring e-commerce success: Applying the DeLone and McLean Information Systems Success Model. International Journal of Electronic Commerce, 9(1), 31-47. https://doi.org/10.1080/10864415.2004.11044317

Delice, E.K. and Gungor, Z. (2009). The Usability Analysis with Heuristic Evaluation and Analytic Hierarchy Process'. International Journal of Industrial Ergonomics, 39(6), pp. 934-939. 
Green, D. T., and Pearson, J. M. (2011). Integrating website usability with the electronic commerce acceptance model. Behaviour and Information Technology, 30(2), 181-199. https://doi.org/10.1080/01449291003793785

Hasan L., Morris A., Probets S. (2009). Using Google Analytics to Evaluate the Usability of E-Commerce Sites. In: Kurosu M. (eds) Human Centered Design. HCD 2009. Lecture Notes in Computer Science, (5619). Springer, Berlin, Heidelberg. https://doi.org/10.1007/978-3-642-02806-9_81

Huang, X., Dai, X., and Liang, W. (2014). BulaPay: a novel web service based third-party payment system for e-commerce. Electronic Commerce Research, 14(4), 611-633. https://doi.org/10.1007/s10660-014-9172-1

Hui-Jiun, H., Jen, Y. and Shing-Sheng, G. 2008. A Study on the Interface Usability of B2C Hypermarket E-commerce Websites. Proceedings of APSCC 2008, The IEEE Asia-Pacific Services Computing Conference. Yilan, Taiwan, December 9-12, 1202-1207.

Ishizaka, A., and Labib, A. (2011). Review of the main developments in the analytic hierarchy process. Expert Systems with Applications, 38(11), 14336-14345. https://doi.org/10.1016/j.eswa.2011.04.143

Kannaiah, Desti, R. S. (2015). The Impact of Augmented Reality on E-commerce. Journal of Marketing and Consumer Research, 64-73.

Karavdic, M., and Gregory, G. (2005). Integrating e-commerce into existing export marketing theories: A contingency model. Marketing Theory, 5(1), 75-104. https://doi.org/10.1177/1470593105049602

Khajouei, R., Zahiri Esfahani, M., and Jahani, Y. (2017). Comparison of heuristic and cognitive walkthrough usability evaluation methods for evaluating health information systems. Journal of the American Medical Informatics Association, 24(e1), e55-e60. https://doi.org/10.1093/jamia/ocw100

Kirk, K., Abrahams, A.S. (2017). Evaluating Public Charity Websites. Nonprofit Management and Leadership, 27(4), 475-91. http://doi.wiley.com/10.1002/nml.21256 (December 7, 2017).

Knezevic, B., Davidaviciene, V., Skrobot, P. (2017). Social Networks as a Communication Tool in Social Supermarkets. In SOTICS 2017,The Seventh International Conference on Social Media Technologies, Communication, and 
Informatics ， Athens: Think https://www.thinkmind.org/index.php?view=articleandarticleid=sotics_2017_1_40_ 68008 (March 6, 2018)

Kuan, H. H., Bock, G. W., and Vathanophas, V. (2005). Comparing the effects of usability on customer conversion and retention at e-commerce websites. Proceedings of the Annual Hawaii International Conference on System Sciences, 00(C), 174. https://doi.org/10.1109/hicss.2005.155

Laudon, K. C., Traver, K. G. (2016). E-Commerce 2016: Business, Technology, Society. 12th edition. Pearson. https://www.pearson.com/us/highereducation/product/Laudon-E-Commerce-2016-Business-Technology-Society-12thEdition/9780133938951.html (March 7, 2018).

Moreno, F. et al. (2016). The Role of Perceived Value and Emotions in the Satisfaction and Future Intentions of Spectators. Engineering Economics, 27(2), 221-29. http://www.inzeko.ktu.lt/index.php/EE/article/view/12288 (March 6, 2017)

Nielsen, J. (1994). Heuristic Evaluations. In: Nielsen, J. and Mack, R.L.. (eds). Usability Inspection Methods. New York, USA; John Wiley and Sons.

Opricovic, S., and Tzeng, G. H. (2004). Compromise solution by MCDM methods: A comparative analysis of VIKOR and TOPSIS. European Journal of Operational Research, 156(2), 445-455. https://doi.org/10.1016/S0377-2217(03)00020-1

Panda, S. K., Swain, S. K., and Mall, R. (2015). An Investigation into Usability Aspects of E-Commerce Websites Using Users' Preferences. Advances in Computer Science: An International Journal, 4(1), 65-73.

Ranganathan, C. and Ganapathy, S. (2002).Key dimensions of business-toconsumer web sites. Information and Management, 39 (6), 57-465, ISSN 03787206, https://doi.org/10.1016/S0378-7206(01)00112-4

Pappas, I. O., Kourouthanassis, P. E., Giannakos, M. N., and Chrissikopoulos, V. (2017). Sense and sensibility in personalized e-commerce: How emotions rebalance the purchase intentions of persuaded customers. Psychology and Marketing, 34 (10), 972-986. https://doi.org/10.1002/mar.21036

Polson PG, Lewis C, Rieman J, Wharton C. Cognitive walkthroughs: a method for theory-based evaluation of user interfaces. Int J Man-machine Stud. 1992, 36 (5), 741-773. 
Saaty, T.L., 1980. The Analytic Hierarchy Process. McGraw-Hill, New York.

Saridakis, G., Benson, B. Ezingeard, J., Tennakoon, H. (2015). Individual Information Security, User Behaviour and Cyber Victimisation: An Empirical Study of Social Networking Users. Technological Forecasting and Social Change 102, 320-30. http://www.sciencedirect.com/science/article/pii/S0040162515002590 (October 8, 2015).

Singh, P. R., Pandita, R., Kalyanaraman, K., and Chhabra, G. S. (2018). Career Guidance System. International Journal of Advanced Research in Computer and Communication Engineering, 171-175. https://doi.org/10.17148/IJARCCE

Travis, D. (2002). E-Commerce Usability. E-Commerce Usability. https://doi.org/10.1201/9780203245910

Tarafdar, M., and Zhang, J. (2007). Determinants of reach and loyalty - A study of website performance and implications for website design. Journal of Computer Information Systems, 48(2), 16-24. https://doi.org/10.1080/08874417.2008.11646005

Tucker, S. P. (2008). E-commerce standard user interface: An E-menu system. Industrial Management and Data Systems, 108 (8), 1009-1028. https://doi.org/10.1108/02635570810904587

Tullis, T. and Albert, W. (2008). Measuring The User Experience: collecting, analyzing, and presenting usability metrics. Morgan Kaufmann.

Wharton C, Rieman J, Lewis C, Polson P. (1994). The cognitive walkthrough method: a practitioner's guide. Usability Inspection Methods. Wiley and Sons,105140

Zhang, Y., Fang, Y., Wei, K. K., Ramsey, E., McCole, P., and Chen, H. (2011). Repurchase intention in $\mathrm{B} 2 \mathrm{C}$ e-commerce - A relationship quality perspective. Information and Management, 48(6), 192-200. https://doi.org/10.1016/j.im.2011.05.003

Zhao, X., Zou, Y., Hawkins, J. and Madapusi, B. (2007). A Business-ProcessDriven Approach for Generating E-commerce User Interfaces. Model Driven Engineering Languages and Systems, 4735, 256-270. 